\title{
Low bone mineral density is related to atherosclerosis in postmenopausal Moroccan women
}

\author{
Ihsane Hmamouchi ${ }^{1}$, Fadoua Allali ${ }^{* 1,2}$, Hamza Khazzani ${ }^{1}$, Loubna Bennani ${ }^{1}$, \\ Leila EL Mansouri ${ }^{1}$, Linda Ichchou ${ }^{1}$, Mohammed Cherkaoui ${ }^{3}$, \\ Redouane Abouqal ${ }^{2}$ and Najia Hajjaj-Hassouni ${ }^{1,2}$
}

\begin{abstract}
Address: ${ }^{1}$ Laboratory of Information and Research on Bone Diseases (LIRPOS). Department of Rheumatology, El Ayachi hospital, University Hospital of Rabat-Sale, Morocco, ${ }^{2}$ Laboratory of Biostatistical, Clinical and Epidemiological Research (LBRCE). Faculty of Medicine and Pharmacy, Rabat, Morocco and ${ }^{3}$ Department of Radiology, Cheikh Zayd University Hospital, Rabat, Morocco

Email: Ihsane Hmamouchi - i.hmamouchi@yahoo.fr; Fadoua Allali* - fadouaallali@yahoo.fr; Hamza Khazzani - hamzakhazani@yahoo.fr; Loubna Bennani - loubnabennani29@yahoo.fr; Leila EL Mansouri - la_mansouri1@yahoo.fr; Linda Ichchou - ilinda19@yahoo.fr; Mohammed Cherkaoui - cherk.m@menara.ma; Redouane Abouqal - abouqal@invivo.edu; Najia HajjajHassouni - nhajjajhassouni@gmail.com

* Corresponding author
\end{abstract}

Published: 14 October 2009

BMC Public Health 2009, 9:388 doi: I0.1 I86//47|-2458-9-388
Received: 24 January 2009

Accepted: 14 October 2009

This article is available from: http://www.biomedcentral.com/147I-2458/9/388

(c) 2009 Hmamouchi et al; licensee BioMed Central Ltd.

This is an Open Access article distributed under the terms of the Creative Commons Attribution License (http://creativecommons.org/licenses/by/2.0), which permits unrestricted use, distribution, and reproduction in any medium, provided the original work is properly cited.

\begin{abstract}
Background: Some studies have implicated several possible metabolic linkages between osteoporosis and vascular calcification, including estrogen deficiency, vitamin $D$ excess, vitamin $K$ deficiency and lipid oxidation products. Nevertheless, it remains unclear whether osteoporosis and atherosclerosis are related to each other or are independent processes, both related to aging. The aim of this cross-sectional study was to evaluate the correlation between arterial thickening and bone status in a sample of apparently healthy Moroccan women.
\end{abstract}

Methods: Seventy-two postmenopausal women were studied. All patients were without secondary causes that might affect bone density. Bone status was assessed by bone mineral density (BMD) in lumbar spine and all femoral sites. Arterial wall thickening was assessed by intima-media thickness (IMT) in carotid artery (CA) and femoral artery (FA). Prevalent plaques were categorized into four groups ranging from low echogenicity to high echogenicity.

Results: The mean age was $59.2 \pm 8.3$ years. $84.7 \%$ had at least one plaque. By Spearman Rank correlation, CA IMT was negatively correlated to Femoral total BMD ( $r=-0.33)$, Femoral neck BMD $(r=-0.23)$, Ward triangle BMD $(r=-0.30)$ and Trochanter BMD $(r=-0.28)$ while there was no association with lumbar BMD. In multiple regression analysis, CA IMT emerged as an independent factor significantly associated with all femoral sites BMD after adjusting of confounding factors. FA IMT failed to be significantly associated with both Femoral and Lumbar BMD. No significant differences between echogenic, predominantly echogenic, predominantly echolucent and echolucent plaques groups were found concerning lumbar BMD and all femoral sites BMD

Conclusion: Our results demonstrate a negative correlation between bone mineral density (BMD) qnd carotid intima-media thickness (IMT) in postmenopausal women, independently of confounding factors. We suggest that bone status should be evaluated in patients with vascular disease to assess whether preventive or therapeutic intervention is necessarry. 


\section{Background}

Atherosclerosis and osteoporosis are two of the most common diseases that are correlated with the health of elderly women. Both are often seen in the same individual. These conditions progress silently until a fracture or myocardial infarction occurs $[1,2]$.

Previous studies have shown an association between osteoporosis and aortic [3-5] and carotid atherosclerosis [6], cardiovascular mortality [7,8], stroke [7] and all-cause mortality [9] in women and men. Both osteoporosis and vascular calcification have largely been attributed to the aging process. Recent studies have shown, however, that arterial calcification is a highly regulated process, with intriguing similarities to bone turnover $[10,11]$ that may be age-independent. The nature of the relationship between osteoporosis and atherosclerosis remains unclear. Some studies have implicated several metabolic linkages between osteoporosis and vascular calcification. These include estrogen deficiency [12], vitamin D excess [13], vitamin K deficiency [14], and lipid oxidation products [15].

Measurement of the far-wall intima-media thickness (IMT) of the common carotid artery (CA) and femoral artery (FA) by high-resolution ultrasonography has been established as a clinically useful index for identifying early-stage general and local atherosclerosis in lower extremities, because CA IMT is correlated strongly with the presence of coronary artery disease [16-18] and FA IMT with local atherosclerosis [19].

The aim of this cross-sectional study was to evaluate the correlation between bone mineral density and artery IMT, a measure of preclinical atherosclerosis, in a sample of apparently healthy postmenopausal Moroccan women.

\section{Methods \\ Subjects}

The study involved 72 consecutive, ambulatory, Moroccan, postmenopausal women living in urban centre of Morocco who were sent to our outpatient Bone Densitometry Center. Recruitment was based on voluntary enrolment. All subjects were referred to this center for osteoporosis risk factors, including menopause. Osteoporosis was assessed by BMD and defined according to the world Health Organization (WHO) $(<2,5$ standard deviation of normal values for young people). Study inclusion criteria were: (1) postmenopausal status (at least 1 year of menopause). Exclusion criteria included having a history of: (1) taking drugs known to influence bone metabolism in the past 2 years, such as vitamin D, calcium, corticosteroids, bisphosphonates and hormone replacement therapy; (2) musculoskeletal, thyroid, parathyroid, adrenal, hepatic, or renal disease; (3) malignancy, (4) hysterectomy; and (5) history of atherosclerotic heart disease or stroke. The study was approved by ethical committee of University-hospital Mohamed V Souissi and all participants provided written consent.

\section{Data collection and measurements}

Each patient completed a questionnaire on sociodemographic parameters, atherosclerosis and osteoporosis risk factors. The age of menopause, the time since menopause, the personal history of cigarette smoking or alcohol intake and the number of pregnancies were recorded.

For the evaluation of physical activity, we used the short form of the International Physical Activity Questionnaire (IPAQ) [20]. The items of IPAQ were structured to provide separate scores on walking, moderate-intensity and vigorous-intensity activity. Computation of the total score requires summation of the duration (in minutes) and frequency (days) of walking, moderate-intensity and vigorous-intensity activities [21].

\section{Anthropometric data}

Weight and height were measured without clothes or shoes at the time of bone densitometry measurements. The Body mass index (BMI) was calculated as body weight/height ${ }^{2}\left(\mathrm{~kg} / \mathrm{m}^{2}\right)$. The inter-assay CV of QC pools was $3 \%$.

\section{Biochemical measurements}

Morning fasting samples of venous blood were taken. Serum total cholesterol (CT, enzymatic colorimetric methods; reference value (RV) 1.4-2.4 g/l), serum highdensity lipoprotein (HDL, enzymatic colorimetric methods; RV,0.50-0.75 g/l), low-density lipoprotein (LDL, enzymatic colorimetric methods; RV 0.65-1.75 g/l), triglycerides (TG, enzymatic colorimetric methods; RV 0.22$2.00 \mathrm{~g} / \mathrm{l}$ ) were measured. Serum Calcium (Ca, kinetic colorimetric assay, RV, 84-97 mg/l); Phosphorus ( $\mathrm{P}$, kinetic colorimetric assay, RV, 27-45 mg/l) and serum creatinine( $\mathrm{Cr}$, kinetic colorimetric assay, RV,5.1-9.5 mg/l) were also measured. Osteocalcin (OC; ECLIA (electrochimiluminescence); RV, $15-46 \mathrm{ng} / \mathrm{ml}$; Elecsys $\mathrm{N}$-Mid Osteocalcin), fasting urine cross-linked carboxy-terminal telopeptide of type I collagen corrected by urinary creatinine (CTX, ECLIA (electrochimiluminescence); RV, 1.008 $\mathrm{ng} / \mathrm{ml}$; Elecsys bCross laps) were determined as bone turnover markers. All theses measurements have been made using Intégra 400 (Roche diagnostics; Mannheim, Germany). Moreover, Serum 25 (OH)VitD (25-hydroxyvitamin D; chimiluminescence; (RV) 20-60 $\mu \mathrm{g} / \mathrm{ml}$; Liaison, Diasorin) and intact PTH (PTH; ECLIA 
(electrochimiluminescence); RV, $15-65 \mathrm{pg} / \mathrm{ml}$; Elecsys Intact PTH) were assayed.

\section{Bone mineral density (BMD)}

Lumbar spine, trochanter, femoral neck and total hip BMD were measured by dual-energy X-ray absorptiometry with a Lunar prodigy densitometer. Daily quality control was carried out by measurement of a Lunar phantom. At the time of the study, phantom measurements showed stable results. The phantom precision expressed as the $\mathrm{CV}(\%)$ was 0.08 . Both $\mathrm{T}$ and $\mathrm{Z}$ scores were obtained. In the T-score calculations, the manufacturer's ranges for European population reference were used because of the absence of a Moroccan data base.

\section{Ultrasonography of the carotid artery (CA) and femoral artery (FA)}

Ultrasonographic examination of the CA and FA was performed in the supine position by the use of high-resolution B-mode ultrasonography performed with an ultrasonography scanner (Xp10 128 ART-upgraded; Acuson, Mountain View, CA), as previously described [22]. To avoid inter-observer variability, all measurements were performed by the same examiner who was unaware of subject characteristics. We recorded atherosclerotic plaques from six sites of the carotid artery: The near and far walls of both internal carotid arteries, the bifurcation segment of the common carotid artery, and the common carotid artery from the bifurcation segment to as far downstream of the supraclavicular region as technically possible; if more than one plaque was present at one of the six sites, the thickest plaque was chosen for analysis. Moreover ultrasound (US) imaging of the femoral arteries was carried out at the level of the bifurcation on both the right and left sides. Atherosclerotic plaque was defined as localized protrusion of the internal part of the vessel wall into the lumen. Plaque morphology in terms of echogenicity, defined as reflectance of the emitted ultrasound signal, was assessed by the use of a visual analogue technique along a gray scale [22]. Plaques that appeared black or almost black (like fluent blood inside the vessel) were described as grade 1 (echolucent, low echogenic), whereas plaques that appeared white or close to white (echogenic), similar to the bright echo zone produced by the mediaadventitia interface in the far wall of the carotid artery, were classified as grade 4 . Grade 2 and grade 3 plaques were interpolated between grades 1 and 4 along the blackwhite scale, the grade 2 plaques consisting of more echolucent than echogenic materials and the grade 3 plaques vice versa. If one single plaque was present and the echogenicity inside this plaque was heterogeneous, the dominant echogenicity determined the grading. When more than one plaque was present, the echogenicity was graded considering the overall plaque area [22]. The mean coefficient of variation [23] for the difference between IMT measurement obtained in repeated examinations performed by the same examiner was 3.2\%.

\section{Statistical analysis}

Statistical analysis was performed with the Windows 13.0 version of SPSS software (SPSS Inc., Chicago, IL, USA). Values are expressed mean \pm S.D or percentages. Normality of the data was tested with a one-sample Kolmogorov Smirnov test to indicate the appropriateness of parametric testing. The correlation coefficients were calculated by Pearson Rank correlation analyses due to normal distribution of various clinical variables. Multiple regression analysis was performed to assess independent association with lumbar spine BMD and femoral BMD. For the relation between plaque echogenicity and $\mathrm{BMD}$, the comparison between groups was made using analysis of covariance (ANOVA). P-values of $<0.05$ were considered as statistically significant.

\section{Results \\ Clinical variables, intima-media thickness and bone density of patients}

Characteristics of participants enrolled in this cross sectional study are shown in table 1 . The mean age and BMI was $59.2 \pm 8.3$ years and $27.7 \pm 4.5 \mathrm{~kg} / \mathrm{m}^{2}$ respectively. Of the 72 persons included in the study, $55.6 \%$ were osteoporotic and $84.7 \%$ had at least one plaque. The means of triglycerides, serum total Cholesterol, high-density lipoprotein and low-density lipoprotein were within normal limits for reference laboratory. The means of CA and FA IMT were to $0.8 \pm 0.4 \mathrm{~mm}$ and $0.8 \pm 0.3 \mathrm{~mm}$ respectively. $36.1 \%$ of Patients had femoral plaque and $59.7 \%$ had carotid artery plaque. Plaques were distributed, according to the echogenity, as follows: $31.9 \%$ Type I echolucent, $16.7 \%$ Type II predominantly echolucent, 9.7\% type III predominantly echogenic and $26.4 \%$ type IV echogenic.

The means of serum Calcium, Phosphorus, 25OH D3, intact PTH, CTX and osteocalcin were within normal limits for reference laboratory (results not shown in table 1).

There were no significant differences among the groups osteoporotic versus no osteoporotic in age, age of menopause, BMI, Physical activity score. Serum Calcium, Phosphorus, $25 \mathrm{OH}$ D3, total Cholesterol, high-density lipoprotein, low-density lipoprotein, Triglycerides, Intact PTH, Osteocalcine, Cross laps and Creatinine were not different and except for $25 \mathrm{OH}$ D3, were within normal limits for reference laboratory. On the basis of vascular ultrasound examination, the prevalence of artery plaques for any of the sites examined was not significantly different in patients with or without osteoporosis $(\mathrm{p}=0.393)$. No significant association was observed concerning the plaque morphologic echography $(\mathrm{p}=0.241)$. Results were shown table 2. 
Table I: Characteristics of study participants

\begin{tabular}{|c|c|}
\hline Number & $\begin{array}{c}72 \\
\text { Mean (SD) }\end{array}$ \\
\hline Age (years) & $59.2 \pm 8.3$ \\
\hline Years since menopause (years) & $12.0 \pm 8.2$ \\
\hline Number of pregnancies & $5.2 \pm 3.4$ \\
\hline Body mass index $(\mathrm{kg} / \mathrm{m} 2)$ & $27.7 \pm 4.5$ \\
\hline Physical activity score (min/week) & $3448 \pm 1053$ \\
\hline Systolic blood pressure $(\mathrm{mmHg})$ & $137 \pm 17$ \\
\hline \multicolumn{2}{|l|}{ Serum level } \\
\hline Triglyceride $(g / l)$ & $1.3 \pm 0.7$ \\
\hline Total Cholesterol $(\mathrm{g} / \mathrm{l})$ & $2.1 \pm 0.3$ \\
\hline high-density lipoprotein $(\mathrm{g} / \mathrm{l})$ & $0.5 \pm 0.1$ \\
\hline low-density lipoprotein $(g / l)$ & $1.2 \pm 0.3$ \\
\hline CA IMT (mm) & $0.8 \pm 0.4$ \\
\hline FA IMT (mm) & $0.8 \pm 0.3$ \\
\hline Lumbar spine BMD (g/cm²) & $0.917 \pm 0.172$ \\
\hline Trochanter BMD $\left(\mathrm{g} / \mathrm{cm}^{2}\right)$ & $0.669 \pm 0.121$ \\
\hline Femoral neck BMD (g/cm²) & $0.823 \pm 0.109$ \\
\hline Ward triangle BMD $\left(\mathrm{g} / \mathrm{cm}^{2}\right)$ & $0.645 \pm 0.140$ \\
\hline \multirow[t]{2}{*}{ Femoral total BMD $\left(\mathrm{g} / \mathrm{cm}^{2}\right)$} & $0.860 \pm 0.111$ \\
\hline & Number (Percentage) \\
\hline Current smoking & $2(2.8)$ \\
\hline Osteoporosis & $40(55.6)$ \\
\hline History of personal peripheral osteoporotic fractures & $13(18.1)$ \\
\hline Number of individuals with plaque & $61(84.7)$ \\
\hline Femoral Plaque & $26(36.1)$ \\
\hline Carotid Plaque & $43(59.7)$ \\
\hline \multicolumn{2}{|l|}{ Plaques echogenicity } \\
\hline No plaque & II (I5.3) \\
\hline Type I echolucent & $23(31.9)$ \\
\hline Type II predominantly echolucent & $12(16.7)$ \\
\hline Type III predominantly echogenic & $7(9.7)$ \\
\hline Type IV echogenic & $19(26.4)$ \\
\hline
\end{tabular}

CA: carotid artery, IMT: intima-media thickness, FA: Femoral artery

\section{Correlations between CA IMT, FA IMT and clinical variables and BMD}

Table 3 shows the summary of correlations of IMT with clinical variables including BMD by Pearson Rank correlation. Only Age was positively correlated with both CA and FA IMT. CA IMT was negatively correlated to Trochanter BMD, Femoral neck BMD, Ward triangle BMD and Femoral total $\mathrm{BMD}$ (figure 1) while there was no association with lumbar BMD. FA IMT failed to be significantly associated with both Femoral and Lumbar BMD.

\section{Multiple regression analysis of factors independently associated with BMD}

In multiple regression analysis, CA IMT was an independent factor significantly associated with Trochanter BMD, Ward triangle BMD, Femoral Neck BMD, femoral total BMD but not lumbar spine BMD after adjusting of age, age of menopause, serum LDL cholesterol, systolic blood pressure and physical activity. Serum LDL cholesterol emerged as an independent factor significantly associated with femoral BMD (table 4).

\section{BMD and plaques echogenicity}

No significant differences between echogenic, predominantly echogenic, predominantly echolucent and echolucent plaques groups were found concerning lumbar BMD and all femoral sites BMD (data not shown).

\section{Discussion}

The most important finding in the present study is that CA IMT emerged as an independent factor that is associated significantly with Trochanter BMD, Femoral neck BMD, Ward triangle BMD and Femoral total BMD, but not with lumbar spine BMD. The association between trabecular or cortical osteoporosis and calcification in different vascular beds may vary, and should be considered when comparing the reported findings. In many studies evaluating the association between low bone mass and vascular calcification, there was an independent association between BMD at cortical sites, as represented by low hip BMD and vascular calcification $[6,12,24]$. However, studies measuring $\mathrm{BMD}$ at predominantly trabecular sites, namely spinal sites, failed to demonstrate this association $[4,6,24,25]$. In 
Table 2: Characteristics of study participants after splitting them in osteoporotic and no osteoporotic

\begin{tabular}{|c|c|c|c|}
\hline & Osteoporosis & Non osteopotic patients & P value ${ }^{a}$ \\
\hline Number & 40 & 32 & \\
\hline \multicolumn{4}{|l|}{ Number of individuals with plaque } \\
\hline Femoral Plaque & $19(47.5)$ & $16(50.0)$ & 0.393 \\
\hline Carotid Plaque & $2(5.0)$ & $I(3.1)$ & 1.000 \\
\hline \multicolumn{4}{|l|}{ Plaques echogenicity } \\
\hline Type I echolucent & $5(12.5)$ & $6(22.2)$ & $0.24 I$ \\
\hline Type II predominantly echolucent & $8(20.0)$ & $2(06.2)$ & \\
\hline Type III predominantly echogenic & $3(7.5)$ & $7(21.8)$ & \\
\hline Type IV echogenic & $3(7.5)$ & $2(06.2)$ & \\
\hline \multicolumn{4}{|l|}{ Mean (SD) } \\
\hline Age (years) & $59.1 \pm 6.2$ & $58.7 \pm 6.5$ & 0.797 \\
\hline Menopause age (yeras) & $48.6 \pm 5.5$ & $48.0 \pm 6.2$ & 0.724 \\
\hline Number of pregnencies & $6.0 \pm 2.6$ & $4.0 \pm 2.0$ & 0.193 \\
\hline Body mass index $(\mathrm{kg} / \mathrm{m} 2)$ & $28.3 \pm 4.0$ & $26.3 \pm 5.1$ & 0.193 \\
\hline Physical activity score & $2160 \pm 1546$ & $3690 \pm 2134$ & 0.200 \\
\hline \multicolumn{4}{|l|}{ Serum level } \\
\hline Triglyceride $(g / l)$ & $1.25 \pm 0.41$ & $0.97 \pm 0.32$ & 0.094 \\
\hline Total Cholesterol $(\mathrm{g} / \mathrm{l})$ & $2.05 \pm 0.30$ & $2.06 \pm 0.31$ & 0.934 \\
\hline high-density lipoprotein $(g / l)$ & $0.55 \pm 0.12$ & $0.59 \pm 0.19$ & 0.572 \\
\hline low-density lipoprotein $(\mathrm{g} / \mathrm{l})$ & $1.25 \pm 0.24$ & $1.27 \pm 0.24$ & 0.645 \\
\hline Calcium $(\mathrm{mg} / \mathrm{l})$ & $97.33 \pm 5.87$ & $98.14 \pm 5.15$ & 0.533 \\
\hline Phosphorus (mg/l) & $35.80 \pm 4.60$ & $37.20 \pm 3.20$ & 0.348 \\
\hline $25 \mathrm{OH}$ D3 $(\mu \mathrm{g} / \mathrm{l})$ & $15.36 \pm 7.46$ & $16.01 \pm 5.77$ & 0.699 \\
\hline
\end{tabular}

the past, this lack of association had been attributed to methodological pitfalls related to Dual Energy X-ray Absorptiometry (DXA) measurements. In fact, DXA measurements of the spine are confounded by the presence of calcified plaques in adjacent vessels and osteophytes [26]. Nevertheless, the lack of an association at trabecular sites

Table 3: Correlations of IMT in each segment with clinical characteristics and BMD

\begin{tabular}{lcc}
\hline Clinical variables & CA IMT & FA IMT \\
\hline Age (years) & $0.227 *$ & $0.309 *$ \\
Menopause age (years) & $-0.08 \mathrm{I}$ & 0.005 \\
Body mass index $(\mathrm{kg} / \mathrm{m} 2)$ & 0.087 & 0.042 \\
Systolic blood pressure $(\mathrm{mmHg})$ & 0.038 & -0.195 \\
Triglyceride $(\mathrm{g} / \mathrm{l})$ & -0.077 & -0.015 \\
High-density lipoprotein $(\mathrm{g} / \mathrm{l})$ & 0.053 & 0.235 \\
Low-density lipoprotein $(\mathrm{g} / \mathrm{l})$ & 0.003 & 0.275 \\
Physical activity score & 0.024 & -0.094 \\
Lumbar spine BMD $\left(\mathrm{g} / \mathrm{cm}^{2}\right)$ & -0.131 & 0.071 \\
Femoral total BMD $\left(\mathrm{g} / \mathrm{cm}^{2}\right)$ & $-0.330 *$ & -0.054 \\
Femoral neck BMD $\left(\mathrm{g} / \mathrm{cm}^{2}\right)$ & $-0.237 *$ & 0.041 \\
Ward triangle BMD $\left(\mathrm{g} / \mathrm{cm}^{2}\right)$ & $-0.301 *$ & -0.078 \\
Trochanter BMD $\left(\mathrm{g} / \mathrm{cm}^{2}\right)$ & $-0.280 *$ & -0.110 \\
& &
\end{tabular}

Values indicate bivariate correlation coefficients (Pearson's rho) obtained from 72 healthy Moroccan women. CA: carotid artery, IMT: intima-media thickness, FA: Femoral artery.

$* p<0.05$ was confirmed by the Sinnot study [27] that used highly sensitive and specific quantitative computerized tomography (QCT) measures of exclusively trabecular bone of the vertebrae. By contrast, previous studies have shown a negative association between lumbar BMD and IMT, but this lack of association has also been described in hemodialysis patients [28].

Our results indicate that FA IMT is not associated significantly with BMD. Our data seem to be in contrast to the earlier findings [5-8] that found a significant association between FA IMT and bone status. It is also conceivable that atherosclerotic distribution within the vascular tree may vary considerably between vascular beds, and this may explain some of the apparently conflicting findings in the literature $[24,29,30]$.

Another finding in the present study was that CA IMT is associated significantly with all femoral site BMD independently of age. Indeed, both osteoporosis and atherosclerosis increase with age, but the relationship between them has remained unclear [31,32]. In some studies, the apparent association between BMD and vascular calcification disappeared after adjusting for age [25,31-33], while in others, the association was independent of age $[3,14,33]$. 


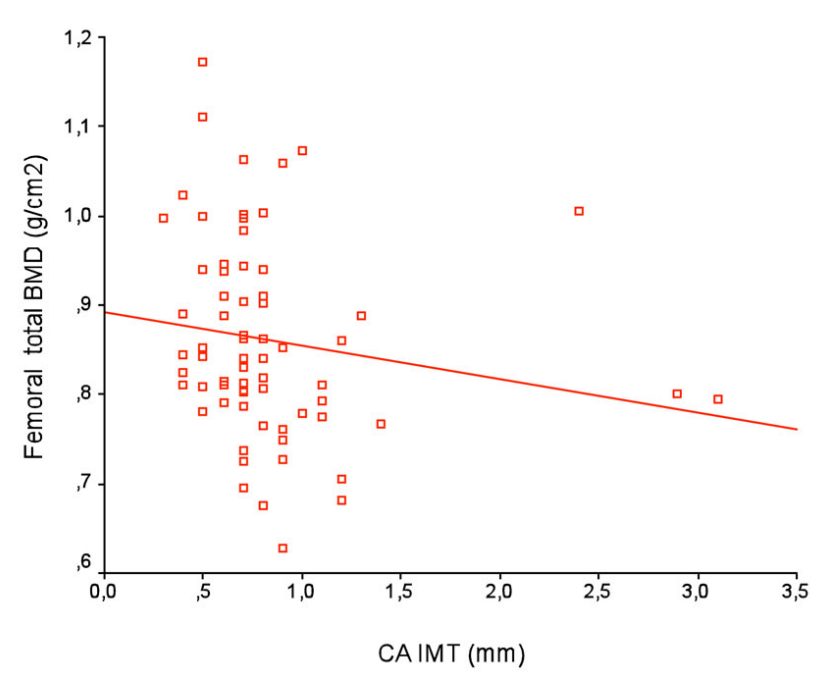

Figure I

Correlation of Carotid artery intima-media thickness (CA IMT) with femoral total BMD. A significant negative correlation was found between Femoral total BMD and CA IMT $(r=-0.237, p=0.006)$ by Pearson analysis.

The biological explanation for the possible relationship between atherosclerosis and osteoporosis is unclear at present, but several hypotheses have been proposed. Oxidized lipids [15], impaired vitamin K status [14], homocysteine, and high levels of osteoprotegerin $[10,11]$ are among the factors that may contribute to the association between atherosclerosis and osteoporosis. Hamerman [34] reviewed several possibilities, and pointed out that inflammation is likely to be one of the processes that influence atherogenesis and bone loss. Many of the inflammatory mediators driving atherogenesis in the arterial wall are known to be in the circulation as markers of cardiovascular risk. These could gain access to bone, where, together with local cytokines, they could enhance the release of osteoblastic factors, that in turn promote osteoclastogenesis.

Table 4: Stepwise regression analysis of factors independently associated with BMD included CA IMT.

\begin{tabular}{lllll}
\hline & FT BMD & W BMD & FN BMD & T BMD \\
\cline { 2 - 5 } & $\beta$ & $\beta$ & $\beta$ & $\beta$ \\
\hline Age & $-0.015^{*}$ & $-0.019^{*}$ & $-0.001^{*}$ & $-0.014^{*}$ \\
LDL & $0.238^{*}$ & 0.151 & $0.241^{*}$ & 0.078 \\
CA IMT & $-0.467^{*}$ & $-0.054^{*}$ & $-0.383^{*}$ & $-0.489^{*}$ \\
\hline
\end{tabular}

LDL: low-density lipoprotein, CA: carotid artery, IMT: intima-media thickness, BMD: bone mineral density, FT: Femoral total, W: Ward triangle, FN: Femoral neck, T: Trochanter.

Confounding factors are: Age, Menopause Age, systolic blood pressure, physical activity, LDL and CA IMT

Values are standard regression coefficient $(\beta) .{ }^{*} p<0.05$
Several researchers have suggested a role for hyperlipidemia and lipid oxidation [15] and inflammation [34]. In vitro studies have shown that oxidized lipids promote osteoblastic differentiation of vascular cells and inhibit such differentiation in bone cells [35]. One possible mechanism by which this may occur is through accumulation of oxidized lipids in tissue so as to mimic chronic infection, thereby stimulating an immune response that promotes the hardening of soft tissue (to wall off infectious agents) and the softening of hard tissue (to dissolve a substrate for growth of infectious agents). In our study, serum LDL cholesterol emerged as an independent factor that is associated significantly with femoral BMD, after adjusting for age and CA IMT.

Although several studies have shown that increasing BMD is related to a decreasing prevalence of echogenic plaque $[36,37]$, our results found no significant differences between the four groups according to the plaque echogenicity in lumbar and femoral BMD.

There are several potential limitations to this cross-sectional study. First, the subjects were not recruited from the community at large, but were selected from patients who underwent bone density determinations. This selection bias may explain the relatively high prevalence of osteoporosis in the subjects studied. In fact, we have already shown that 31 to $39 \%$ of post-menopausal women had osteoporosis [38-40]. Another bias is related to the classification of plaques. Despite the fact that the reproducibility of plaque echogenicity was good, some misclassification may have occurred. Lastly, we have no direct histopathological demonstration that increased IMT is due to atherosclerosis. The arterial thickening might have been due to another, non-atherosclerotic arteriopathy. However, IMT measurements are still useful in that IMT is strongly correlated with the presence of coronary artery diseases.

\section{Conclusion}

In brief, our results showed that decreased BMD is correlated with increased CA IMT in postmenopausal women, independently of confounding factors. We suggest that bone status should be evaluated in patients with vascular disease to assess whether preventive or therapeutic intervention is necessary.

\section{Competing interests}

The authors declare that they have no competing interests.

\section{Authors' contributions}

FA and NHH conceived the study and supervised its design, execution, and analysis and participated in the drafting and critical review of the manuscript. IH, FA and RA did data management and statistical analyses. All other 
authors enrolled patients, participated in data acquisition and critical revision of the manuscript. IH wrote the paper with input from all investigators. All authors read and approved the final manuscript.

\section{Acknowledgements}

This study has been supported by the Universite Mohammed V Souissi, Rabat, Morocco.

The Laboratory of Royal Gendarmerie supported the Biochemical measures. We wish to express special thanks to its director, Dr Saâd El Kabbaj.

\section{References}

I. NIH: Consensus Development Panel on Osteoporosis Prevention, Diagnosis, and Therapy. Osteoporosis prevention, diagnosis, and therapy. JAMA 200I, 285:785-795.

2. Aronow WS, Silent MI: Prevalence and prognosis in older patients diagnosed by routine electrocardiograms. Geriatrics 2003, 58:24-28.

3. Kiel DP, Kauppila LI, Cupples LA, Hannan MT, O_Donnell CJ, Wilson PW: Bone loss and the progression of abdominal aortic calcification over a $\mathbf{2 5}$ year period: the Framingham Heart Study. Calcif Tissue Int 200I, 68:27I-276.

4. Tanko LB, Bagger YZ, Christiansen C: Low bone mineral density in the hip as a marker of advanced atherosclerosis in elderly women. Calcif Tissue Int 2003, 73:15-20.

5. Schulz E, Arfai K, Liu X, Sayre J, Gilsanz V: Aortic calcification and the risk of osteoporosis and fractures. J Clin Endocrinol Metab 2004, 89:4246-4253.

6. Uyama O, Yoshimoto $Y$, Yamamoto $Y$, Kawai A: Bone changes and carotid atherosclerosis in postmenopausal women. Stroke 1997, 28: I730-1732.

7. Browner WS, Seeley DG, Vogt TM, Cummings SR: Non-trauma mortality in elderly women with low bone mineral density. Study of Osteoporotic Fractures Research Group. Lancet 1991, 338:355-358.

8. Recke $P$ Von der, Hansen MA, Hassager $C$ : The association between low bone mass at the menopause and cardiovascular mortality. Am J Med 1999, 106:273-278.

9. Center JR, Nguyen TV, Schneider D, Sambrook PN, Eisman JA: Mortality after all major types of osteoporotic fracture in men and women: an observational study. Lancet 1999, 353:878-882.

10. Doherty TM, Asotra K, Fitzpatrick LA, Qiao JH, Wilkin DJ, Detrano RC, Dunstan CR, Shah PK, Rajavashisth TB: Calcification in atherosclerosis: bone biology and chronic inflammation at the arterial crossroads. Proc Natl Acad Sci USA 2003, 100: II20I-II206.

II. Tintut $Y$, Demer LL: Recent advances in multifactorial regulation of vascular calcification. Curr Opin Lipidol 200I, I 2:555-560.

12. Barengolts El, Berman M, Kukreja SC, Kouznetsova T, Lin C, Chomka $\mathrm{EV}$ : Osteoporosis and coronary atherosclerosis in asymptomatic postmenopausal women. Calcif Tissue Int 1998 62:209-2/3

13. Moon J, Bandy B, Davison AJ: Hypothesis: Etiology of atherosclerosis and osteoporosis: are imbalances in the calciferol endocrine system implicated? J Am Coll Nutr 1992, I I:567-583.

14. Jie KG, Bots ML, Vermeer C, Witteman JC, Grobbee DE: Vitamin K status and bone mass in women with and without aortic atherosclerosis: a population-based study. Calcif Tissue Int 1996, 59:352-356.

15. Tintut Y, Morony S, Demer LL: Hyperlipidemia promotes osteoclastic potential of bone marrow cells ex vivo. Arterioscler Thromb Vasc Biol 2004, 24:6-10.

16. Salonen R, Salonen JT: Progression of carotid atherosclerosis and its determinants: a population-based ultrasonography study. Atherosclerosis 1990, 81:33-40.

17. Lekakis JP, Papamichael CM, Cimponeriu AT, Stamatelopoulos KS, Papaioannou TG, Kanakakis J, Alevizaki MK, Papapanagiotou A, Kalofoutis AT, Stamatelopoulos SF: Atherosclerotic changes of extracoronary arteries are associated with the extent of coronary atherosclerosis. Am J Cardiol 2000, 85:949-952.
18. Simons PC, Algra A, Bots ML, Grobbee DE, Graaf $Y$ van der: Common carotid intima-media thickness and arterial stiffness: indicators of cardiovasucular risk in high-risk patients. The SMART Study (Second Manifestation of ARTerial disease). Circulation 1999, 100:951-957.

19. Taniwaki H, Shoji T, Emoto M, Kawagishi T, Ishimura E, Inaba M, Okuno Y, Nishizawa Y: Femoral artery wall thickness and stiffness in evaluation of peripheral vascular disease in type 2 diabetes mellitus. Atherosclerosis 200I, I58:207-2/4.

20. Craig CL, Marshall AL, Sjöström M, Bauman AE, Booth ML, Ainsworth BE, Pratt M, Ekelund U, Yngve A, Sallis JF, Oja P: International Physical Activity Questionnaire: I 2-country reliability and validity. Med Sci Sports Exerc 2003, 35: I38I-1395.

21. Ainsworth BE, Haskell WL, Leon AS, Jacobs DR Jr, Montoye HJ, Sallis JF, Paffenbarger RS Jr: Compendium of physical activities: an update of activity codes and MET intensities. Med Sci Sports Exerc 2000, 32:S498-S5I6.

22. Joakimsen O, Bønaa KH, Stensland-Bugge E: Reproducibility of ultrasound assessment of carotid plaque occurrence, thickness, and morphology. The Tromsø Study. Stroke 1997, 28:220I-2207.

23. Bland JM, Altman DG: Statistical methods for assessing agreement between two methods of clinical measurement. Lancet 1986, I:307-310.

24. Klift M Van der, Pols HA, Hak AE, Witteman JC, Hofman A, de Laet $C E$ : Bone mineral density and the risk of peripheral arterial disease: the Rotterdam Study. Calcif Tissue Int 2002, 70:443-449.

25. Vogt MT, San Valentin R, Forrest KY, Nevitt MC, Cauley JA: Bone mineral density and aortic calcification: the Study of Osteoporotic Fractures. J Am Geriatr Soc 1997, 45: I 140- I45.

26. Drinka PJ, DeSmet AA, Bauwens SF, Rogot A: The effect of overlying calcification on lumbar bone densitometry. Calcif Tissue Int 1992, 50:507-510.

27. Sinnott B, Syed I, Sevrukov A, Barengolts E: Coronary calcification and osteoporosis in men and postmenopausal women are independent processes associated with aging. Calcif Tissue Int 2006, 78: 195-202.

28. Raggi P, Giachelli C, Bellasi A: Interaction of vascular and bone disease in patients with normal renal function and patients undergoing dialysis. Nat Clin Pract Cardiovasc Med 2007, 4:26-33.

29. Cheng YJ, Church TS, Kimball TE, Nichaman MZ, Levine BD, McGuire DK, Blair SN: Comparison of coronary artery calcium detected by electron beam tomography in patients with to those without symptomatic coronary heart disease. Am J Cardiol 2003, 92:498-503.

30. Danielsen R, Sigvaldason H, Thorgeirsson G, Sigfusson N: Predominance of aortic calcification as an atherosclerotic manifestation in women: the Reykjavik study. I Clin Epidemiol 1996, 49:383-387.

31. Aoyagi K, Ross PD, Orloff J, Davis JW, Katagiri H, Wasnich RD: Low bone density is not associated with aortic calcification. Calcif Tissue Int 200I, 69:20-24

32. Frye MA, Melton LJ 3rd, Bryant SC, Fitzpatrick LA, Wahner HW, Schwartz RS, Riggs BL: Osteoporosis and calcification of the aorta. Bone Miner 1992, 19:185-194.

33. Reid IR, Ames RW, Evans MC, Sharpe SJ, Gamble GD: Determinants of the rate of bone loss in normal postmenopausal women. J Clin Endocrinol Metab 1994, 79:950-954.

34. Hamerman D: Osteoporosis and atherosclerosis: biological linkages and the emergence of dual-purpose therapies. QJM 2005, 98:467-484.

35. Parhami F, Morrow AD, Balucan J, Leitinger N, Watson AD, Tintut $Y$, Berliner JA, Demer LL: Lipid oxidation products have opposite effects on calcifying vascular cell and bone cell differentiation. A possible explanation for the paradox of arterial calcification in osteoporotic patients. Arterioscler Thromb Vasc Biol 1997, 17:680-687.

36. Jørgensen L, Joakimsen O, Rosvold Berntsen GK, Heuch I, Jacobsen BK: Low bone mineral density is related to echogenic carotid artery plaques: a population-based study. Am J Epidemiol 2004 160:549-556.

37. Saverino A, Del Sette M, Conti M, Ermirio D, Ricca M, Rovetta G, Gandolfo C: Hyperechoic plaque: an ultrasound marker for osteoporosis in acute stroke patients with carotid disease. Eur Neurol 2006, 55:31-36. 
38. Allali F, El Aichaoui S, Khazani H, Benyahia B, Saoud B, El Kabbaj S, Bahiri R, Abouqal R, Hajjaj-Hassouni N: High Prevalence of Hypovitaminosis D in Morocco: Relationship to Lifestyle, Physical Performance, Bone Markers, and Bone Mineral Density. Semin Arthritis Rheum 2009, 38:444-45I.

39. Allali F, Maaroufi H, Aichaoui SE, Khazani H, Saoud B, Benyahya B, Abouqal R, Hajjaj-Hassouni N: Influence of parity on bone mineral density and peripheral fracture risk in Moroccan postmenopausal women. Maturitas 2007, 57:392-398.

40. Allali F, El Aichaoui S, Saoud B, Maaroufi H, Abouqal R, Hajjaj-Hassouni $N$ : The impact of clothing style on bone mineral density among post menopausal women in Morocco: a case-control study. BMC Public Health 2006, 6: 135.

\section{Pre-publication history}

The pre-publication history for this paper can be accessed here:

http://www.biomedcentral.com/1471-2458/9/388/pre pub

Publish with Bio Med Central and every scientist can read your work free of charge

"BioMed Central will be the most significant development for disseminating the results of biomedical research in our lifetime. "

Sir Paul Nurse, Cancer Research UK

Your research papers will be:

- available free of charge to the entire biomedical community

- peer reviewed and published immediately upon acceptance

- cited in PubMed and archived on PubMed Central

- yours - you keep the copyright

Submit your manuscript here:

http://www.biomedcentral.com/info/publishing_adv.asp 